\title{
EL TESTAMENTO DE DON JUAN MOGROVEJO DE LA CERDA
}

\author{
Guillermo Lohmann Villena
}

Publicada en el número anterior del Boletín una semblanza de la múltiple personalidad de don Juan Mogrovejo de la $\mathrm{Cerda}^{1}$, me complace adicionar aquella nota biográfica con el texto de la última disposición de voluntad del fecundo escritor y precisar la fecha de su fallecimiento. Abrigaba esperanzas de que en dicho documento se contuviesen atractivas noticias sobre la labor literaria del testador y se alumbrasen rincones oscuros tocantes a su trayectoria biográfica, pero tales expectativas se han visto frustradas y he de reconocer mi decepción. El silencio sobre esos extremos es absoluto.

1. Número 30, segundo semestre de 1998, pp. 9-32. En vía de ribete, aunque confinado en nota, allegamos un poder escriturado por Mogrovejo de la Cerda en 13 de julio de 1629, por el que facultaba al canónigo del Cabildo metropolitano de Lima, doctor Bartolomé de Benavides y de la Cerda -cuyo segundo apellido pregona el parentesco- (promovido en 1639 a obispo de Antequera (Nueva España), para gestionarle mercedes, un cargo de Corregidor, o una renta situada sobre tributos de indios (Archivo General de la Nación. Protocolo de Cristóbal de Arauz, 1629-1630 (133), fol. 335). 
Gracias al gentil envío del investigador cusqueño licenciado Donato Amado González, podemos dar a la publicidad el tenor del testamento cerrado de Mogrovejo de la Cerda, al que precedieron las formalidades de ley para su apertura. Merced a estas diligencias, que comienzan con la fe de muerte del otorgante, sabemos que nuestro autor expiró el lunes 5 de octubre de 1665 en "las casas de su continua morada ques enfrente del combento de santa catalina". Los testigos instrumentales de la comprobación del escrito reconocieron bajo juramento y con su firma la autenticidad del mismo así como la apertura del pliego por el Corregidor General Luis Ibáñez de Peralta y Cárdenas, Caballero de Santiago. Desfilaron los capitanes y Regidores Luis Enríquez de Monroy y Agustín Jara de la Cerda, alcalde de la Hermandad del Cuzco; Lorenzo Félix de Benavente y el Presbítero Bachiller Alonso Márquez Dávila. En la plica constan además de los anteriores, las firmas de Martín Sánchez Ortuño, Diego de Cárdenas y el Bachiller Bartolomé de Arrúe.

Mogrovejo de la Cerda dictó su disposición testamentaria a mediodía de la víspera de su óbito, y premiosamente alcanzó a firmarla con el pulso muy trémulo ${ }^{2}$. He aquí la transcripción del documento:

En el nombre de dios amen. Sepan $\mathrm{q}^{\text {tos }}$. esta carta vieren como yo don $\mathrm{Ju}^{\circ}$. mogrobexo de la cerda comisario de la caualleria desta ciud ${ }^{\mathrm{d}}$. del cuzco hijo Lexitimo de Don $\mathrm{Ju}^{\circ}$. de mongrovexo (sic) y de doña ysauel de la cerda difuntos Estando como estoy Enfermo de Enfermedad que dios nuestro $\mathrm{S}^{r}$. a sido seruido de me dar y en mi buen juicio y entendim ${ }^{\text {to }}$. natural tal qual dios nuestro $\mathrm{S}^{r}$. fue seruido de darme creyendo como firme y berdaderamente creo En el misterio de la $\mathrm{S}^{\mathrm{ma}}$. trinidad $\mathrm{p}^{\mathrm{e}}$. hijo y espiritu santo tres perss ${ }^{\text {as }}$. y vn solo dios verdadero y en todo aque-

2. Archivo Departamental del Cuzco. Protocolo de Lorenzo de Mesa Andueza. Legajo 203, 1665, fols. 895-900v. 
llo que creE y confiesa La santa madre yglesia En cuya creencia protesto viuir y morir y porque La muerte es cosa natural a toda critura (sic) bibiente deseando poner mi anima en carrera de saluacion y descargar mi consiencia hago y otorgo mi testam ${ }^{10}$. En la manera sigte.

primeram $^{\text {te }}$. encomiendo $\mathrm{mi}$ anima a dios nro. $\mathrm{S}^{\mathrm{r}}$. que la crio y rredimio con su presiosa sangre y el cuerpo a la tierra de que fue formado = mando que $\mathrm{q}^{\mathrm{d} o}$. La boluntad de dios nuestro $\mathrm{S}^{\mathrm{r}}$. fuere seruido de lleuarme desta uida mi cuerpo sea amortaxado con el auito de san fran ${ }^{c o}$. y enterrado en la capilla del carmen de la yglesia de mi $\mathrm{p}^{\mathrm{e}}$. san $\operatorname{aug}^{\mathrm{n}}$. desta ciu ${ }^{\mathrm{d}}$. y me acompañe El cura y sacristan de la catedral con cruz alta y el demas acompañamiento que pareciere a mis aluaceas y este dia se me diga vna misa cantada de cuerpo presente con su biJilia y su cera e vino y de todo se pague La Limosna acostumbrada de mis bienes.................................... mando se den a las mandas forçosas y rredemp ${ }^{\text {on }}$. de cautiuos a todas ellas quatro $\mathrm{p}^{8 \mathrm{~s}} .=\mathrm{Y}$ a Los santos Lugares de Jerusalen otros quatro $p^{\mathrm{ss}} .=\ldots \ldots \ldots \ldots \ldots \ldots$ declaro que fui casado con doña fran ${ }^{\text {ca }}$. de rrojas hija Lexitima del cap ${ }^{\mathrm{n}}$. Ju${ }^{0}$. de La fuente y de doña $\mathrm{Ju}^{\mathrm{a}}$. de rroxas y al tienpo que me casse con ella me dieron En dote La cant ${ }^{d}$. de pesos que constara por vn libro que tiene por titulo en el pergamino Libro de lo que deuo y $\mathrm{E}$ de auer El qual Entrego al $\mathrm{p}^{\mathrm{e}}$. hernando de ozerin de la compañia de Jesus mi confessor para que lo guarde y de su cumplimiento en todo $=\mathrm{y}$ de dho. matrim ${ }^{\circ}$. tuue quatro hijos. El prim $^{\circ}$. doña ysauel de la cerda cassada en potossi con andres aguado y no Le deuo dote ninguna $=\mathrm{y}$ el segundo el muy $\mathrm{rr}^{\mathrm{do}}$. $\mathrm{p}^{\mathrm{e}}$. fray $\mathrm{Ju}^{\circ}$. de mogrovexo rreligiosso de mi $\mathrm{p}^{\mathrm{e}}$. $\operatorname{san} \mathrm{fran}^{\mathrm{co}}$. = y el tercero es doña clara de mogrovexo casada con don fernan ${ }^{\text {do }}$. de carrion a la qual no Le di dote ning ${ }^{\mathrm{a}}$. $\mathrm{y}$ al $\mathrm{L}^{\mathrm{d}}$. don manuel mogrovexo presvitero a quien tanpoco no Le e dado nada sino alimentadole hasta oy............... declaro que mi hijo fray $\mathrm{Ju}^{\circ}$. de mogrovexo quando profeso hiço rrenunciacion En mi de su Lexitima 
con las condiciones que della constara....

declaro que los vienes que tenia quando murio mi primera mugr. Los dexo declarados En el dho. mi libro que esta en $\mathrm{p}^{r}$. del dho. $\mathrm{p}^{\mathrm{t}}$. hernando ose rin... yten declaro que segunda bez me case con doña bernardina de espinossa y la dote que me dieron con La susodha. Esta declarado En dho. mi libro questa En $\mathrm{p}^{\mathrm{r}}$. de mi confesor como tanbien La hacienda que yo tenia quando contraxe El dho. segundo matrimonio $=\mathrm{y}$ durante El Emos porcreado (sic) por nros. hijos leJitimos a doña maria mogrovexo monja profesa en el $\mathrm{m}^{\circ}$. de $\mathrm{S}^{\mathrm{ta}}$. clara cuyo dote que se llevo al dho. mon $^{\text {rio }}$. es de vn censo que ympuse sobre mis haciendas que tengo en xaxaguana como consta de la escrip ${ }^{a}$. otorgada ante el presente escriu ${ }^{\circ}$. y el ajuar y selda que poseE se la dio el $\mathrm{p}^{\mathrm{e}}$. fray $\mathrm{Ju}^{\circ}$. de mogrovexo su hermano = y la dha. doña bernardina ayudo con tres cientos pesos poco mas / o menos = y asimismo huuimos deste dho. $\mathrm{m}^{\circ}$. a don toribio alfonso mogrovexo colexial en el colexio rreal de san anton abad.

declaro por mis vienes todo Lo que tengro declarado en el dho. mi Libro questa En $\mathrm{p}^{\mathrm{r}}$. de mi confessor...... yten declaro que deuo todas Las cantidades questan Escritas y declaradas En dho. mi Libro y fuera dellas deuo a algunos mercaderes de esta ciu ${ }^{d}$. algunas cantidades de pesos como constara de sus libros cuyas partidas y deudas son de poca cantidad mando que todas Las dhas. deudas se paguen de mis vienes............................................. yten declaro que deuo muchas cantidades de pesos Las quales tengo escritas y declaradas En dho. libro assi de censsos como de vnas casas de que proceden y todo lo demas que constare por escrituras y cedulas autenticas o de otra manera que juridicamente deuo pagar se paguen de mis vienes....................... yten declaro que me deuen muchas cantidades questan Escritas y declaradas en el dho. mi Libro mando que se cobren y se pongan por mis vienes.................................................... yten mando se digan por mi anima Las missas que 
a mis aluaceas pareciere $=y$ rruego a mis herederos y a la $\mathrm{S}^{\mathrm{ra}}$. doña bernardina mi mugr. que Luego que falleciere Embien setenta y dos $\mathrm{p}^{\mathrm{s}}$. al convento mayor de la congregon. de nra. $\mathrm{S}^{\text {ra }}$. de la $\mathrm{O}$ de que $\mathrm{E}$ sido prefecto para que me rresciua En el dho. convento y partisipe de Los sufraxios............................ y para cumplir y pagar Este mi testamento dexo y nombro por mis aluaceas al $\mathrm{p}^{\mathrm{e}}$. hernando oserin de la comp ${ }^{i}$. de Jesus mi confesor y al $\mathrm{p}^{\mathrm{e}}$. fray $\mathrm{Ju}^{\circ}$. mogrovexo mi hijo y a doña bernardina de espinoza mi mugr. y a la susodha. por tenedora de mis vienes y les doy $p^{r}$. qual En tal caso se rrequiere para que executen Como en el se $\mathrm{q}^{\mathrm{e}}$. En todo tpo. avnque sea pasado el año del albaceazgo que para ello Les prorrogo

y cumplido y pagado este mi testamento mandas y legados en el contenidos y en el dho. mi Libro del rremanente que quedare de mis vienes dexo y nombro por mis herederos a doña clara de rroxas mogrovexo doña ysauel de la cerda mogrovexo y al $\mathrm{L}^{\mathrm{do}}$. don manuel mogrobexo de la cerda y a doña maria mogrovexo - Y a don toribio alfonso mogrovexo mis hijos Lexitimos para que lo ayan y hereden por yguales partes tanto el vno como el otro con la bendicion de dios y la mia........................... Con lo qual rreboco $\mathrm{Y}$ anulo otros qualesq ${ }^{r}$. testamentos poderes para testar codicilos y otros ynstrumentos que antes deste aya fecho que quiero y mando ninguno dellos balga saluo este que al pres ${ }^{\text {te }}$. hago y otorgo ante el pres ${ }^{\text {te }}$. escriu ${ }^{\circ}$. que balga por mi vltima boluntad o en aquella via y forma que aya Lug $^{\mathrm{r}}$. de dr ${ }^{\circ}$. y asi lo otorgo y firmo de mi nombre en la ciudad del cuzco en quatro dias del mes de otubre de mill E seis ${ }^{6}$. y sesenta y cinco años E yo el escriu ${ }^{\circ}$. doy fee $\operatorname{con}^{\circ}$. al otorgante.

Don $\mathrm{Ju}^{\circ}$. Mogrouejo de la cerda

Ante mi

Lorensso De messa Andueza sc ${ }^{\circ} \cdot \mathrm{pu}^{\circ}$. 